\title{
DO BULLYING AO PRECONCEITO: OS DESAFIOS DA BARBÁRIE À EDUCAÇÃO*
}

\author{
Deborah Christina Antunes \\ Antônio Álvaro Soares Zuin \\ Universidade Federal de São Carlos, São Carlos, Brasil
}

\begin{abstract}
RESUMO: O objetivo deste artigo é realizar uma análise crítica de um tipo de violência escolar que vem sendo estudado no Brasil nos últimos anos, denominado bullying. Para isso, apresenta inicialmente seu conceito, a descrição dos comportamentos enquadrados, suas classificações, causas e determinantes. Por meio da crítica à razão instrumental realizada principalmente por Adorno e Horkheimer, denuncia-se como o conceito de bullying pertence a uma ciência pragmática que atende à manutenção da ordem vigente ao invés de colaborar para a emancipação dos indivíduos. Por fim, ao apresentar o conceito de preconceito aponta que se trata do mesmo fenômeno e que, como indicado pelos autores da Escola de Frankfurt, não deve ser combatido via imperativos morais, mas pela reconstituição da capacidade de experienciar nas diversas relações sociais vividas.
\end{abstract}

PALAVRAS-CHAVE: Teoria Crítica; bullying; preconceito; Adorno, Theodor Wiesengrund.

\section{FROM BULLYING TO PREJUDICE: THE CHALLENGES FROM BARBARISM TO EDUCATION}

ABSTRACT: The aim of this article is to achieve a critical analysis on one kind of school violence, called bullying, that has been studied in Brazil in the last couple of years. To do this, it begins introducing the concept of bullying, description of typical behaviors, its inner classifications, causes and determinants. By using critique to instrumental reason made by Adorno and Horkheimer, it reveals how the concept of bullying concerns to one pragmatic science that answers to a status quo instead of collaborating to the individual's emancipation. Finally, it shows the concept of prejudice and concludes that both are the same phenomenon, and as indicated by the authors of Frankfurt School, must not be combated with moral imperatives, but by the reconstitution of the capacity to have experiences in the various social relationships lived.

KEYWORDS: Critical Theory; bullying; prejudice; Adorno, Theodor Wiesengrund.

“. . . desbarbarizar tornou-se a questão mais urgente da educação hoje em dia" (Adorno, 1971/2003).
O "hoje em dia" de Adorno, da epígrafe, refere-se à Alemanha das décadas de 1950 e 1960, palco recente de um dos maiores genocídios que a humanidade já presenciou e realizou. No entanto, transposta à realidade educacional brasileira, essa frase não perde o valor, e com isso concordam muitos daqueles que vivenciam a violência dentro das escolas, e também daqueles que a conhecem de longe, por meio dos noticiários alarmantes, também formadores de opinião.

A preocupação com a violência no ambiente escolar, segundo Sposito (2001), emergiu nos estudos acadêmicos brasileiros a partir da década de 1980, ou seja, parece que a preocupação com a barbárie e o compromisso com uma educação contra a violência são ainda muito recentes no Brasil - apenas 26 anos. Mas, de fato, a história da educação no Brasil, comparada com o Velho Mundo, é recente. Segundo Sposito (2001), o estudo da violência escolar parte da análise das depredações e danos aos prédios escolares e chega ao final da década de 1990 e início dos anos 2000 com o estudo das relações interpessoais agressivas, envolvendo alunos, professores e outros agentes da comunidade escolar. De acordo com Abramovay e Rua (2003), a violência escolar é um fenômeno antigo em todo o mundo e configura um "gra- 
ve problema social", podendo ocorrer, conforme já classificado pela ciência e adotado pelo senso comum, como indisciplina, delinqüência, problemas de relação professor-aluno ou mesmo aluno-aluno, entre outros. Segundo Martins (2005), vários são os conceitos existentes que envolvem a violência na escola, além dos citados, tais como conduta anti-social, distúrbio de conduta e bullying, conceitos estes decorrentes de estudos realizados em diversas partes do mundo, revelando-se uma das grandes preocupações das sociedades industrializadas.

Embora atualmente o estudo da violência tenha classificado suas diversas formas de apresentação e ocorrência nas escolas públicas e privadas, tais como a presença de gangues, de armas e do tráfico de drogas nas instituições escolares, a análise que se pretende realizar neste artigo é a respeito de uma delas, que se convencionou chamar no mundo todo, de bullying, denominação inglesa surgida na década de 1970 na Noruega, adotada atualmente por países europeus e africanos, além de Austrália, Japão, Estados Unidos, Canadá (Smith, Cowie, Olaffson \& Liefooghe, 2002) e nos últimos anos, pelo Brasil, como nos trabalhos de Almeida Jr. e Queda (2007) e Chiorlin (2007).

Esse tipo de violência, que tem sido objeto de investigação em alguns estudos nacionais e divulgado cotidianamente pela mídia ${ }^{2}$, é conceituado como um conjunto de comportamentos agressivos, físicos ou psicológicos, como chutar, empurrar, apelidar, discriminar e excluir (Lopes Neto, 2005; Smith, 2002), que ocorrem entre colegas sem motivação evidente, e repetidas vezes, sendo que um grupo de alunos ou um aluno com mais força, vitimiza um outro que não consegue encontrar um modo eficiente para se defender (Lopes Neto, 2005; Martins, 2005; Rigby, 2002; Smith, 2002). Tais comportamentos são usualmente voltados para grupos com características físicas, sócio-econômicas, de etnia e orientação sexual, específicas (Smith, 2002). Alguns estudos apontam que ciganos, artistas de circo, estrangeiros e outros grupos nômades (Lloyd \& Stead, 1998, 2001), além dos alunos obesos (Griffiths, Wolke, Page, Horwood \& ALSPAC, 2005; Sjöberg, Nilsson \& Leppert, 2005) e acima do peso (Janssen, Craig, Boyce \& Pickett, 2004), os de baixa estatura (Stein, Frasier \& Stabler, 2004) e os homossexuais e filhos de homossexuais (Clarke, Kitzinger \& Potter, 2004; Holmes \& Cahill, 2003; Ray \& Gregory, 2001), são, estatisticamente, mais alvos de seus colegas do que crianças e jovens considerados "normais".

Martins (2005) identifica o bullying em três grandes tipos. Segundo a autora, baseando-se no estudo teórico de produções na área, o que se chama por bullying é dividido da seguinte maneira: diretos e físicos, que inclui agressões físicas, roubar ou estragar objetos dos colegas, extorsão de dinheiro, forçar comportamentos sexu- ais, obrigar a realização de atividades servis, ou a ameaça desses itens; diretos e verbais, que incluem insultar, apelidar, "tirar sarro", fazer comentários racistas ou que digam respeito a qualquer diferença no outro; e indiretos que incluem a exclusão sistemática de uma pessoa, realização de fofocas e boatos, ameaçar de exclusão do grupo com o objetivo de obter algum favorecimento, ou, de forma geral, manipular a vida social do colega. Lopes Neto (2005) alerta para um novo modo de intimidação, chamada cyberbullying, que na verdade é a utilização da tecnologia da comunicação (celulares e internet, por exemplo) para a realização desta violência.

Além desse conceito geral, os autores que trabalham no estudo desse fenômeno fazem referência à função do bullying para aquele que o pratica. Segundo Lopes Neto (2005), sua função é a realização da afirmação de poder interpessoal por meio da agressão, o que vai ao encontro do que Martins (2005) defende, a saber, que autores do bullying costumam agir com dois objetivos, primeiro para demonstrar poder, e segundo para conseguir uma afiliação junto a outros colegas. Há também, segundo Fante (2005), Lopes Neto (2005) e Smith (2002), a diferenciação de papéis. Assim haveria os intimidadores (líderes ou seguidores), as vítimas (passivas, agressivas provocadoras, e vítimas que também intimidam outros) e os não participantes (os que reforçam a intimidação, os que participam ativamente dela e que poderiam entrar na categoria de intimidadores seguidores, aqueles que apenas observam, e os que defendem o colega ou buscam por ajuda).

Alguns autores dissertam também a respeito de suas causas, que incluem, além de fatores econômicos, sociais e culturais, os relacionados ao temperamento do indivíduo, às influências familiares, de colegas, da escola e da comunidade (Lopes Neto, 2005), às relações de desigualdade e de poder, tidas como naturais por Smith (2002), a uma relação negativa com os pais e um clima emocional frio em casa, e às relações de poder existentes no ambiente escolar (Yoneyama \& Naito, 2003).

De fato, a violência conceituada como bullying é observada nas escolas - e em outros ambientes como no trabalho, na casa da família, nas forças armadas, prisões, condomínios residenciais, clubes e asilos como apontam Fante (2005) e Smith (2002). Porém, antes de prontamente aceitar esta definição e classificação, é necessário refletir a respeito da medida em que elas possibilitariam a compreensão do cerne da violência. Apesar da divulgação ampla de tal conceito e de ter adentrado com todas as forças nas discussões sobre violência escolar no Brasil, nota-se a dificuldade de encontrar algum estudo que se proponha a investigar criticamente o bullying. Iniciar uma reflexão nesse sentido é a proposta desse artigo. 


\section{O bullying e a razão coisificada}

Os estudos com base apenas em dados estatísticos e no diagnóstico de sua ocorrência, as intervenções baseadas em modelos de uma educação pré-determinada, assim como sua fácil assimilação e ampla divulgação pelos meios de comunicação de massa, o desolamento causado por suas consequiências e a inquestionável necessidade de intervenção via imperativos morais, denunciam, ainda que apenas pelas lacunas, que tal conceito faz parte de uma ciência instrumentalizada e a serviço da adaptação das pessoas para a manutenção de uma ordem social desigual. É importante que se questione a finalidade do conceito criado pelos pesquisadores da área e adotado inteiramente por alguns colegas brasileiros. Pensar até que ponto a classificação possibilitada pela adoção desta tipologia da violência não mascara os processos sociais inerentes aos comportamentos classificados como bullying, ou mesmo admitindo a existência de tais processos, ao tratá-los como naturais, é o primeiro passo que uma ciência deve dar, se o seu objetivo é, de fato, contribuir para o desenvolvimento da humanidade e não para a mera adaptação dos indivíduos.

Na Dialética do esclarecimento, Adorno e Horkheimer (1969/1985) asseveraram que o conhecimento positivista nascido no século XVIII é totalitário, na medida em que na busca pela dominação da natureza, pelo procedimento eficaz, pelo enaltecimento da disciplina, pela transformação da natureza em objetividade, pela busca de poder e controle, os homens pagam o preço da alienação daquilo sobre o que objetivavam exercer seu poder. E a ciência acaba por controlar os próprios homens, pois seu objetivo inicial de contribuir para a diminuição da fadiga, tanto na dimensão espiritual quanto na física, se reifica, uma vez que a técnica não é mais encarada como um produto da atividade humana e se transforma em sujeito, ao passo que os seres humanos que a produziram se tornam objetos.

Segundo Adorno e Horkheimer (1956/1973), quando a doutrina da sociedade relacionada a um ideal inspirado nos princípios absolutos do ser, encontrada principalmente na antiga filosofia grega, ou mesmo do idealismo alemão, se modificou com o intuito de buscar uma sociologia com propósitos de se libertar, assim como as ciências naturais, das teologias e metafísicas, e se deter na verificação de vínculos causais regulares, houve uma ruptura radical que separou a razão em objetiva e subjetiva, de acordo com a denominação de Horkheimer (1974/ 2002). A primeira se refere à razão que se preocupa com a sua finalidade, sem que para isso deixe de lado os meios de sua realização, e a segunda concerne à razão técnica, instrumental, como denominada posteriormente por Adorno e Horkheimer (1969/1985). Assim, desde Comte, a missão da sociologia positiva (no sentido de ciência pretensamente emancipada dos credos religiosos e da especulação metafísica) é investigar as leis da natureza consideradas imutáveis, importando a exatidão rigorosa da comprovação. Ao pressupor que o movimento social se sujeita, necessariamente, a leis invariáveis, ela se basta com a observação pura, o experimento e o método comparativo (Adorno \& Horkheimer, 1956/1973).

Deste modo, a relação entre a crítica à ciência instrumental, e a classificação estereotipada da violência, fica evidente ao se perceber que ao classificarem os comportamentos, e neste caso, os "tipos" de violência, e, mesmo dentro desses "tipos" classificarem detalhadamente as suas variáveis constituintes, os homens têm a ilusão de que de alguma forma exercem seu controle sobre eles, e que de alguma maneira também conseguem controlar a violência e a natureza, tanto dentro, quanto fora de si. Porém, os fenômenos classificados, contraditoriamente, tornam-se naturais, pois se deixa de lado a raiz de sua existência, convertendo-os em números e dados estatísticos, e, como atentaram Marx e Engels (1932/1998), aparecem como "uma coleção de fatos sem vida" (p. 20). A contradição está exatamente neste ponto: ao voltarem a ser tratados como naturais passam a exercer seu poder sobre o homem e se tornam mais incontroláveis, pois estão agora mascarados sob o rótulo de ciência.

Entretanto, a importância da ciência e da investigação empírica não é, de modo algum, negada. Para Adorno (1972-1980/2001), os diversos procedimentos investigativos dos quais se valem os pesquisadores das ciências sociais e humanas para coletar opiniões, verificar atitudes e comportamentos reais, tais como questionários, entrevistas, observações, discussões em grupo e experimentos controlados, são, de fato, um avanço do método indutivo de se produzir conhecimentos a respeito da realidade, e das ferramentas de ilustração do pensamento social. No entanto, entende-se que não são por si só suficientes. É necessário que se some a eles a análise sociológica das formas de organização e das forças objetivas da sociedade, de modo a, com impulso crítico, interpretar os dados, mostrar suas múltiplas tensões e questionar o sentido social dos fenômenos singulares encontrados como um meio de desencantamento das construções sociológicas que perderam sua relação com a realidade. Tal análise é fundamental, especialmente porque:

Por vezes o fundamental é falseado, quando não completamente ocultado, pelas definições obtidas por meio da abstração. Enquanto que a investigação social empírica se orgulha da objetividade, porque, imitando as ciências naturais, elimina a subjetividade do observador, em boa parte de sua atividade é ela mesma que permanece presa da subjetividade daqueles aos quais dirige seus questionários e enquetes; presa de suas opiniões, atitudes e com- 
portamentos. Ao invés das condições em que vivem os homens, ou de sua função objetiva no processo social, o que acaba revelando-se são suas imagens subjetivas. (Adorno, 1972-1980/2001, p. 127-128).

Observa-se que os pesquisadores, de forma geral, ao dissertarem sobre as supostas "causas" do que chamam bullying, dentre as quais se destacam os fatores econômicos, sociais, culturais e particulares, não as problematizam. Tal atitude desemboca na defesa da expressão genérica do "educar para a paz" utilizada por Fante (2005). Desta forma, as influências familiares, de colegas, da escola e da comunidade, as relações de desigualdade e de poder, a relação negativa com os pais e o clima emocional frio em casa parecem considerados naturais e apartados das contradições sociais que os produziram. Consequentemente, o que ocorre é a prescrição do bom comportamento e da boa conduta moral via imperativos de como se deve ou não agir frente àquele que parece diferente, via o velho ditado popular segundo o qual não se deve fazer com os outros o que não se quer que seja feito para si mesmo. Embora tais estudos tenham o mérito de desenvolver classificações e tipologias que tornam visíveis determinadas manifestações de violência, nota-se a importância de que tais definições sejam estudadas à luz das mediações sociais que as determinam. Pois, com a inexistência de uma análise radical, as ações frente à barbárie (denunciada pelos dados quantitativos) se coisificam de forma semelhante à da educação típica da sociedade administrada, que impõe aos homens um modelo de ser e agir visando à sua manutenção e tornando a reflexão desnecessária e improdutiva. Ou seja, ao ir à mesma direção dos imperativos culturais, e reforçando a educação na forma de adestramento, pois é tão instrumentalizada quanto eles, apresenta-se mais uma vez como um padrão de comportamento imposto de fora. Novamente, evidencia-se a hegemonia típica da sociedade "esclarecida", que, ao invés de possibilitar o desenvolvimento da autonomia, conserva o padrão autoritário da cultura. Deste modo, ela caminha num sentido contrário ao de uma educação que possibilitaria a emancipação dos indivíduos, educação esta voltada para a independência intelectual e pessoal e que, segundo Marcuse (1965/2001), embora amplamente reconhecida como discurso, é em sua face verdadeira um projeto subversivo, pois visa a desmascarar a cultura dominante teoricamente democrática que promove a heteronomia sob o rótulo de autonomia, limitando o pensamento e a experiência ao invés de promover sua ampliação.

Porém, embora aqui se teçam críticas ao conceito de bullying, à ciência na qual se baseia e às consequiências de sua utilização sem reflexão crítica, não se pretende diminuir a importância do estudo sobre a violência no ambiente escolar, seja entre os alunos ou em qualquer outro âmbito. Mas deve ficar claro que olhar para essa violência e estudar esses fatos requer uma análise não cristalizada que envolva sim sua problematização, ou seja, a análise da dialética entre indivíduo e sociedade, sem deixar-se seduzir pelo falso controle sugerido pelo culto da sistematização pura e simples. Sem dúvida, é um desafio, mas um desafio necessário de ser enfrentado se de fato o objetivo não é a manutenção do sistema, mas sim a real emancipação dos homens e da sociedade.

\section{Do bullying ao preconceito}

Voltando à afirmação de Adorno da epígrafe, podese compreender agora que ela não foi citada em vão, uma vez que se considera, afinal, que se vive em uma época na qual a barbárie é a condição de existência da própria sociedade capitalista. Trata-se de uma condição que precisa ser mudada e, com ela, a própria lógica social. Assim, desbarbarizar num sentindo amplo não é meramente evitar comportamentos agressivos, admitidos por Adorno (1971/2003) como legítimos em determinados momentos. Para ao menos amainar as práticas bárbaras é necessário refletir a respeito da violência contida no próprio processo civilizatório, processo que, embora tenha produzido avanços científicos e tecnológicos, tem mantido exatamente esta cultura repressiva que possibilita sua reprodução nos e pelos indivíduos submetidos a ela (Adorno, 1971/2003).

Está claro, e até mesmo os pesquisadores do bullying admitem, conforme apresentado inicialmente, que na ocorrência da violência discutida aqui estão envolvidos aspectos culturais (sociais, políticos e econômicos) e individuais. No entanto, é importante ressaltar que, de acordo com o referencial aqui utilizado, tais fatores devem sim ser analisados, problematizados e interpretados, pois não basta mencioná-los. Assim, os fatores individuais fazem referência ao desenvolvimento da personalidade nesse ambiente, e os culturais, além de se referirem à sociedade que limita o desenvolvimento em uma direção específica, também se referem às condições objetivas da incidência dessa violência de uma pessoa para com a outra. Ora, o bullying, tal como conceituado, não é, de maneira alguma, uma simples manifestação da violência sem qualquer fator determinante. Na verdade, o bullying se aproxima do conceito de preconceito, principalmente quando se reflete sobre os fatores sociais que determinam os grupos-alvo, e sobre os indicativos da função psíquica para aqueles considerados como agressores.

Essa proximidade leva à hipótese de que o que atualmente tem sido denominado bullying é um fenômeno há muito conhecido pela humanidade, mas que ganhou nova nomeação pela ciência pragmática que se ilude ao tentar controlá-lo via classificação e aconselhamentos. Somando-se a isso, sua assimilação torna-se imediata numa sociedade que se pretende cinicamente cosmopo- 
lita (sem sê-lo de fato), pois o que assusta e fere a moral burguesa, hegemônica em nosso tempo, é a forma como tem se manifestado no ambiente escolar e as conseqüências que têm trazido, e que tem como exemplos mais extremos os suicídios e os ataques armados à comunidade que resultam em pessoas feridas e mortas.

Defendendo essa hipótese, de que se trata, novamente, ou ainda neste momento histórico, do preconceito existente em sociedades e culturas pretensamente democráticas, mas na realidade autoritárias, torna-se importante apresentar agora o conceito de preconceito referido aqui, bem como os seus determinantes. Este conceito foi trabalhado por Adorno, Frenkel-Brunswik, Levinson e Sandford (1969) quando do estudo que se denominou "A personalidade autoritária", que teve por objetivo buscar as raízes psicológicas do anti-semitismo, e envolve Teoria Crítica e Psicanálise.

A aproximação entre essas duas vertentes teóricas é, segundo Rouanet (1998), não caracterizada como uma influência da psicanálise em relação à Escola de Frankfurt, mas uma "interioridade constitutiva". Assim, a psicanálise habita o próprio corpo teórico da Teoria Crítica permitindo a ela pensar seu objeto, a si mesma, e mesmo a psicanálise freudiana, como um momento da cultura. A Teoria Crítica engloba o marxismo, pela conservação da crítica ao fetichismo da mercadoria, e a psicanálise como ciência do indivíduo desmistificadora que, assim como o materialismo histórico, considera que "o que é alegado como motivo manifesto é um mero pretexto que oculta as verdadeiras correlações e as suas causas reais" (Rouanet, 1998, p. 19).

Partindo desse referencial, o preconceito, de acordo com os psicanalistas Jahoda e Ackerman (1969), é caracterizado por "uma atitude de hostilidade nas relações interpessoais, dirigida contra um grupo inteiro ou contra os indivíduos pertencentes a ele, e que preenche uma função irracional definida dentro da personalidade" (p. 27). Somando a esta conceituação, Crochik (1995) atenta para o fato de que para que ele exista é necessário que se somem às características do indivíduo fatores de seu processo de socialização, e, embora a manifestação do preconceito seja individual, pois responde às necessidades individuais, ele "surge no processo de socialização, como resposta aos conflitos gerados neste processo" (Crochik, 1995, p. 15).

Assim, tendo como base o desenvolvimento infantil, conforme descrito e explicado por Freud (1905/1969), o processo de socialização, nessa sociedade, engendra a internalização da ideologia dominante, de acordo com Rouanet (1998):

A ideologia vai se enraizando no curso do processo de socialização, através das sucessivas privações pulsionais que a instância familiar, e posteriormente as outras instâncias 2 , vão impondo ao indivíduo. $\mathrm{O}$ processo pelo qual os diferentes objetos de amor vão sendo abandonados, no curso do desenvolvimento psicossexual, em que o indivíduo transita da fase oral para a fase genital, é acompanhado, em cada caso, de prescrições e proscrições, de imperativos éticos, de normas negativas e positivas, que correspondem, invariavelmente, aos valores sociais vigentes. (p. 23-24).

O desenvolvimento psicossexual culmina exatamente na constituição do superego quando, por meio da resolução do Complexo de Édipo, as leis, as normas e o sistema de valores vigentes, encarnados na figura paterna, são introjetados pelo sujeito. Deste modo, quando ele chega à fase adulta, tem a sociedade em si mesmo e apresenta-se adequadamente susceptível à obediência à autoridade que se encontra mascarada neste momento histórico em que a ideologia confunde-se com a própria realidade. Exatamente por isso, hoje, a crítica à ideologia constitui-se a partir da crítica à realidade (Rouanet, 1998).

Porém, a simples introjeção da ideologia, dos valores e normas de conduta, não garante uma equivalência entre os desejos individuais e os imperativos sociais, ao contrário, ocorre o que os autores da Escola de Frankfurt chamaram de "reconciliação forçada", ou seja, uma reconciliação aparente entre tais desejos e imperativos sociais. É na medida em que esse antagonismo, entre os desejos do id e as normas da cultura, torna-se cada vez mais insuportável ao ego, que a agressividade para com o outro, mediada pela projeção como mecanismo de defesa, apresenta-se como a manifestação material do preconceito. O outro é visto como um estranho, mas, ao mesmo tempo, como aquele que seria capaz de realizar seus desejos sendo, aos olhos do sujeito preconceituoso, alguém capaz de assim realizar-se integralmente como indivíduo, e que por isso mesmo, por conta desse desejo de individuação impossibilitado de se realizar na sociedade massificada, lhe é familiar. Entretanto, mesmo isso é uma ilusão, é como evidenciaram Adorno e Horkheimer (1969/ 1985), uma falsa projeção, pois o outro está tão culturalmente submetido e tão incapaz de realizar-se como indivíduo quanto àquele que manifesta o preconceito. Assim, a falsa projeção, como fundamento psíquico do anti-semitismo, e do preconceito de um modo geral, significa a incapacidade de o sujeito diferenciar no material projetado o que lhe é de fato característico e o que não é. De acordo com Amaral (1997), ela "não permite nenhuma discriminação entre o mundo exterior e a vida psíquica, nem o afastamento necessário ao processo de identificação que engendraria, ao mesmo tempo, a consciência de si e a consciência moral" (p. 40). É então um mecanismo por meio do qual o sujeito procura livrar-se dos impulsos que ele não admite como seus, por ter introjetado os valores autoritários da cultura, e que, embora lhe pertençam, os atribui - de maneira fantasiosa - ao outro. 
Tais comportamentos, desencadeados em situações em que esses indivíduos se percebem livres como sujeitos, parecem, além de letais às pessoas envolvidas, ser sem sentido, tal como as constatações dos pesquisadores que insistem em não interpretar. No entanto, a aparente falta de objetivo confere verdade à explicação de que isso se caracteriza como uma válvula de escape, uma raiva desencadeada contra aquele que, desamparado, chama a atenção (Adorno \& Horkheimer, 1969/1985).

Ainda assim os grupos, ou mesmo os indivíduos isoladamente, alvos de preconceito, possuem certas características que determinam esse seu "destino". Longe de serem culpados pela agressividade que é voltada contra eles, guardam estreita proximidade com os imperativos culturais: petulantes apresentam-se como sua antítese! Obviamente isso é uma ironia - a antítese retifica a norma vigente, fazendo parte de sua história e tendo um papel fundamental em sua conservação.

Ajudados pelo sentido do desenvolvimento econômico e seu papel dentro dele, pela dinâmica do desenvolvimento das religiões, das sociedades, dos ideais e padrões de beleza e comportamento, segundo Adorno et al. (1969), o objeto do preconceito deve ter características ou poder de ser definido em termos de características que se harmonizam com as tendências psíquicas daquele que manifesta o preconceito, tendências estas criadas socialmente. Algumas são racionalizações que não têm a ver com a realidade, outras expressam suas próprias fraquezas, o que gera estímulos psicologicamente adequados para a destrutividade. Deste modo, o caráter funcional do anti-semitismo fica evidente quando se percebe que o grupo contra o qual se volta parece ser acidental. $\mathrm{O}$ fato é que aqueles que sofrem mais ferozmente a pressão social frequentemente podem tender a transferir essa pressão para outros, que vistos como inimigos imaginários se tornam vítimas. Pode-se perceber então, que não é o preconceito, a barbárie por si própria, esta violência irracional, que desfigura a ordem social, ao contrário, é a ordem estabelecida atualmente que não pode resistir sem desfigurar os próprios homens, ou seja, sem barbarizálos. A perseguição do outro, a repugnância compulsiva do inimigo imaginário, tem por essência a violência cotidiana que se faz manifesta contra tudo aquilo que não conseguiu se ajustar totalmente, ou que acaba por ferir as "certezas" sobre as quais o progresso se sedimentou. (Adorno \& Horkheimer, 1969/1985).

A objetificação do processo social, sua obediência às leis supra-individuais intrínsecas, parece resultar em uma alienação intelectual do indivíduo para com a sociedade. Essa alienação é experienciada pelo indivíduo como desorientação, como medo e incertezas constantes. As atitudes agressivas, estereotipadas e irrefletidas, que caracterizam o preconceito, sejam elas físicas ou psicológicas, oferecem ao sujeito gratificações emocionais e narcísicas que tendem a quebrar as barreiras da autocrítica racional, ao mesmo tempo em que recrudescem a força do pensamento estereotipado. Tais gratificações podem ser o sentimento fugaz de poder e a identificação grupal, ou seja, a ilusão de uma alteridade que já não é garantida na sociedade administrada, que é, ela mesma, ideologia (Adorno et al., 1969). Além disso, segundo Adorno e Horkheimer (1969/1985), o que ocorre é um prazer na tentativa de destruir aquilo que incomoda, e é por isso que se mostra imune aos argumentos racionais sobre a inexistência de sua rentabilidade. Para os mesmos autores:

Se um mal tão profundamente arraigado na civilização não encontra sua justificativa no conhecimento, o indivíduo também não conseguirá aplacá-lo, ainda que seja tão bem intencionado quanto a própria vítima. Por mais corretas que sejam, as explicações e os contra-argumentos racionais, de natureza econômica e política, não conseguem fazê-lo, porque a racionalidade ligada à dominação está ela própria na base do sofrimento. Na medida em que agridem e cegamente se defendem, perseguidores e vítimas pertencem ao mesmo circuito funesto. (Adorno \& Horkheimer, 1969/1985, p. 159).

\section{Os desafios à educação}

Embora as diversas atitudes de violência em relação ao outro, características do preconceito, produzam a priori uma rejeição quase que automática nos indivíduos, nelas ainda pode-se encontrar um ponto relevante. É claro que ninguém pretende defender atos de barbárie, embora se defenda que a própria rejeição ao debate a respeito de tais atos, bem como a rejeição irrefletida aos próprios atos de barbárie, devam ser objetos de reflexão.

A educação, sem dúvida, é um caminho para a superação da barbérie, no entanto carrega ainda atualmente os momentos repressivos da cultura, como a divisão entre o trabalho físico e o trabalho intelectual e o princípio da competição que é contrário a uma educação realmente humana. Ou seja, a educação atual não avança em modelos ideais de um indivíduo autônomo e emancipado conforme as concepções kantianas, mas explicita as relações de heteronomia estabelecidas no mundo para além dos muros escolares. A autoridade é imposta a partir do exterior. Porém é esta idéia de emancipação que precisa ser inserida no pensamento e na prática educacionais, na mão contrária à mera transmissão de conhecimentos e à simples modelagem de pessoas, já que ninguém tem o direito de modelar alguém a partir de seu exterior - seja para o bem ou para o mal alguém não pode decidir pelo outro como deve ou não agir. Pensamento e prática educacionais devem estar na direção de produzir uma consciência verdadeira, em que as ações possam ser de fato 
frutos da razão daqueles que, emancipados, tornam-se capazes de tomar as rédeas das esferas pública e privada de suas próprias vidas (Adorno, 1971/2003).

Não é um plano fácil de ser realizado, principalmente porque o obscurecimento da consciência é resultado da organização em que se vive e da ideologia dominante, ou seja, da totalidade do existente à qual se faz necessário adaptar-se. No entanto, este movimento contínuo de adaptação e ajustamento exigido para se viver em sociedade não pode ser ignorado, pois, caso seja, a educação continuará realizando seu papel de impotente e ideológica. Assim, tanto a entrega cega ao existente, quanto um posicionamento sectário contrário em relação a ele, fazem por vezes o papel de seu mantenedor. O ideal seria um modelo de adaptação que não permitisse ao mesmo tempo a perda de individualidade e proporcionasse a união entre adaptação e resistência pautadas na conscientização e na espontaneidade. Ou seja, que preparasse para a superação permanente da alienação que se baseia na estrutura social, nos modelos de indivíduos socialmente impostos, enfim, nos estereótipos que são um entrave para a experiência, ou melhor, que se colocam entre o sujeito e o objeto com o qual ele deveria se relacionar em sua totalidade (Adorno, 1971/2003).

Os mecanismos de repressão se tenderiam a se dissolver exatamente por essa conscientização que é, por essência, a constituição da aptidão à experiência, abrindo caminho para a formação que se constitui pela permanente tensão crítica entre indivíduo e cultura. Neste sentido, fica claro que não basta pregar a paz pela via da educação, se o educar em si consiste no mesmo adestramento totalitário vigente nesta sociedade, se o que se chama de paz é um imperativo imposto e alheio aos sujeitos, e que por isso continua a garantir a heteronomia, e a ir, na verdade, à mesma direção da educação da disputa e do individualismo, uma vez que prega a "empatia" e a "tolerância" e legitima, desta maneira, a diferença de uma forma valorativa. Mesmo que a intenção seja legítima, como ficou claro até aqui, de acordo com Adorno et al (1969): “Alguém não pode 'corrigir' a estereotipia pela experiência; ele deve reconstituir a capacidade para ter experiências ao invés de prevenir o crescimento de idéias que são malignas, no mais literal sentido clínico" (p. 617, grifo do autor).

É neste sentido que a educação não pode ser postulada exata e pontualmente para a individualidade, pois esta está limitada pela carência de possibilidades sociais de individuação e pelo crescente enfraquecimento da formação do eu, mas deve ser postulada para a recuperação da capacidade de experienciar nas diversas relações sociais vividas. Aqui, compreende-se que é apenas como núcleo que impulsiona a resistência que o indivíduo, neste momento histórico, ainda pode encontrar os meios para manter-se existente (Adorno, 1971/2003).
A antiga, porém ainda atual máxima kantiana, é adotada na busca de uma educação para a emancipação, na busca pelo que Kant (1783/1974) chamou de "indivíduo esclarecido", capaz de fazer uso público e privado de sua própria razão, indivíduo que ousa saber. A via para isso, para conquistar essa forma de agir no mundo ,parece ser, ainda, a reflexão sobre a realidade efetiva e o desmascaramento de seus determinantes atualmente mitificados, naturalizados. A reflexão a respeito da própria semiformação ${ }^{3}$, o auto-reconhecimento de seus próprios limites, desejos e contradições, se mostram como um primeiro passo rumo à autonomia, e à educação como projeto subversivo conforme apontaram os estudiosos da Teoria Crítica da Sociedade, lembrando que a reflexão é compreendida como meio, mas não como ponto final.

É assim que a educação contra a barbárie se recupera, mas com um sentido diferente, porque se faz como crítica à sociedade ideológica que se calcifica nos sujeitos no decorrer de seu processo de socialização. Porque se faz sendo proposição de fins realmente transparentes e humanos, enquanto coragem de "servir-se de si mesmo sem a direção de outrem" (Kant, 1783/1974, p. 100). Desta forma, talvez deixem os homens de serem apenas o meio para a conservação do capital, em um momento em que a história continua a inverter a direção da linha do desenvolvimento humano e, apesar de todo desenvolvimento tecnológico e científico, retorna à selvageria.

\section{Considerações finais}

Pensar o problema da violência nesta sociedade, e, principalmente, da violência irracional no ambiente escolar, considerado um dos grandes responsáveis pela socialização das crianças, e, segundo ambiente de convívio depois do famíliar, é uma questão importante e urgente. Os motivos são inúmeros no que tange às consequiências individuais ligadas principalmente ao sofrimento psíquico e à não adaptação. No entanto falta ainda uma questão: por que o sofrimento psíquico e a não adaptação são problemáticos? Talvez muitos se assustem ao se deparar com esta questão, que parece ser tão obvia, mas o silêncio após ela denuncia que ainda não se sabe ao certo a resposta. Alguns podem arriscar "porque isso é barbárie", "porque é um horror", ou mesmo "porque todos têm o direito de uma boa vida", mas são respostas circulares e unilaterais, e não revelam de fato o que está por trás da tão defendida "saúde" do indivíduo. Será mesmo que a preocupação é com a saúde das pessoas, ou seria, na realidade, uma preocupação com aqueles que poderiam denunciar o falso do sistema, que por não se adaptarem não mantêm a ordem social com a qual eles mesmos sofrem?

O próprio conceito de bullying parece exercer esse papel de adaptação, ao classificar a barbárie, e pretensamente controlá-la por essa via. $\mathrm{O}$ conceito de 
bullying coloca tudo em seu lugar, tenta arrumar e justificar aquilo que fere a ideologia democrática, e acaba por mascarar as tensões e contradições que estão na base da própria barbárie. Esse é o risco que se corre ao se utilizar a mera classificação e quantificação.

Ao contrário, as práticas de violência nas escolas devem ser compreendidas por meio da análise social, das formas de organização e das forças objetivas da sociedade, e de como tais forças se materializam e se calcificam nos sujeitos que se desenvolvem neste meio. Estudar a violência requer também este impulso crítico, tanto nas análises teóricas quanto na interpretação dos dados, de modo a mostrar suas múltiplas tensões e questionar o sentido social dos fenômenos singulares encontrados. Por meio desta análise, reveladora das construções sociológicas, políticas, econômicas, ideológicas, talvez se possa pensar numa outra forma de educação que não a regida pelos imperativos que impedem a emancipação ao forçar a repressão e a adaptação, uma outra forma de educação que não seja ela própria barbárie.

\section{Notas}

* A pesquisa que deu base a este artigo foi financiada pela FAPESP.

1. Na mídia podem ser encontradas reportagens sobre o tema, popularizando sua discussão entre pais, professores, profissionais da saúde, crianças e adolescentes. É o caso, por exemplo, daquelas publicadas em jornais de ampla divulgação como a Folha de São Paulo (Livro ensina, 2006; Veja como enfrentar, 2006) e O Estado de São Paulo (Governo japonês, 2006), no programa Mais Você da Rede Globo Comunicação e Participações, destinado às donas de casa $(2005,2006)$, e em revistas como Nova Escola (Cavalcante, 2004), Istoé (Maldade de menina, 2004), Viver Mente de Cérebro (Schäfer, 2005) e Atrevida (Mercatelli, 2005).

2. Tais instâncias podem ser, por exemplo, a escola, a igreja/religião, os clubes de associações e a indústria cultural como um todo. Além disso, atualmente, segundo Amaral (1997), existe a substituição do pai individual por modelos padronizados, veiculados pelos meios de comunicação em massa, o que implica também mudanças nos mecanismos psíquicos.

3. A semiformaçãoé a formação cultural típica da sociedade atual. Ela substitui a verdadeira formação, impedindo-a ou ao menos dificultando sua possibilidade de existência. Sua característica marcante é a perda do momento emancipador da reflexão, desenvolvendo-se no âmbito da conservação do existente por meio de esquemas de pensamento (tickets) utilizados pelo sujeito para interpretar a realidade. A formação, ao contrário, seria a permanente tensão crítica entre indivíduo e cultura, na qual a apreensão dos conteúdos culturais permitiria a convivência democrática entre os indivíduos (Adorno, 1972-1980/1996).

\section{Referências}

Abramovay, M., \& Rua, M. G. (2003). Violências nas escolas: Versão resumida. Brasília, DF: Unesco.

Adorno, T. W. (1996). Teoria da semicultura (N. Ramos-de-Olivei- ra, Trad.). Educação e Sociedade, 56, 388-411. Retirado em 08 abr. 2007, de http://www.educacaoonline.pro.br (Original publicado em 1972-1980)

Adorno, T. W. (2001) Epistemología y ciencias sociales (V. Gómez, Trad.). Madrid, España: Frónesis Cátedra. (Original publicado em 1972-1980)

Adorno, T. W. (2003). Educação e emancipação (W. L. Maar, Trad.). Rio de Janeiro, RJ: Paz e Terra. (Original publicado em 1971)

Adorno, T. W, Frenkel-Brunswik, E., Levinson, D. J., \& Sandford, R. N. (1969). The authoritarian personality. New York: WW Norton.

Adorno, T. W., \& Horkheimer, M. (1973). Temas básicos da Sociologia (A. Cabral, Trad.). São Paulo, SP: Cultrix. (Original publicado em 1956)

Adorno, T. W., \& Horkheimer, M. (1985). Dialética do esclarecimento: Fragmentos filosóficos (G. A Almeida, Trad.). Rio de Janeiro, RJ: Jorge Zahar. (Original publicado em 1969)

Almeida, A. R., Jr., \& Queda, O. (2007). Bullying escolar, trote universitário e assédio moral no trabalho: Investigação sobre similaridades e diferenças. Antitrote. Retirado em 13 jul. 2007, de http:// www.antitrote.org

Amaral, M. (1997). O espectro de Narciso na modernidade: De Freud a Adorno. São Paulo, SP: Estação Liberdade.

Cavalcante, M. (2004, dez.). Como lidar com brincadeiras que machucam a alma. Revista Nova Escola, 178.

Chiorlin, M. O. (2007). A influência do bullying no processo de ensino-aprendizagem. São Paulo, SP: Universidade Federal de São Carlos.

Clarke, V., Kitzinger, C., \& Potter, J. (2004). Kids are just cruel anyway: Lesbian and gay parents talk about homophobic bullying. British Journal of Social Psychology, 43, 531-550. Retirado em 22 jun. 2006, de http://www.bps.org.uk

Crochik, J. L. (1995). Preconceito, indivíduo e cultura. São Paulo, SP: Robe.

Fante, C. (2005). Fenômeno bullying: Como prevenir a violência nas escolas e educar para a paz(2. ed.). Campinas, SP: Versus.

Freud, S. (1969). Três ensaios sobre a teoria da sexualidade. In S. Freud. Edição eletrônica brasileira das obras psicológicas completas de Sigmund Freud: Vol. 7. Rio de Janeiro, RJ: Imago. (Original publicado em 1905)

Governo japonês pede punição para bullying nas escolas (2006, 29 nov.). O Estado de São Paulo, Caderno Educação. Retirado em 31 jan. 2007, de http://www.estadao.com.br

Griffiths, L. J., Wolke, D., Page, A. S., Horwood, J. P., \& ALSPAC Study Team. (2005). Obesity and bullying: Different effects for boys and girls. Archives of Disease Childhood, 91, 121-125. Retirado em 22 jun. 2006, de http://www.archdischild.com

Holmes, S. E., \& Cahill, S. (2003). School experiences of gay, lesbian, bisexual and transgender youth. Journal of Gay \& Lesbian Issues in Education, 1(3). Retirado em 22 fev. 2007, de http:// www.haworthpress.com

Horkheimer, M. (2002). Eclipse da razão. São Paulo, SP: Centauro. (Original publicado em 1974)

Janssen, I., Craig, W. M., Boyce, W. F., \& Pickett, W. (2004). Associations between overweight and obesity with bullying behaviors in school-aged children. Pediatrics, 113(5), 1187-1194. Retirado em 22 jun. 2006, de http://www.pediatrics.org

Jahoda, M., \& Ackerman, N. W. (1969). Distúrbios emocionais e anti-semitismo. São Paulo, SP: Perspectiva.

Kant, I. (1974). Resposta à pergunta: O que é esclarecimento. In I. Kant. Textos seletos (pp. 100-117). Petrópolis, RJ: Vozes. (Original publicado em 1783) 
Livro ensina pais a prevenir acidentes e evitar bullying, excesso de álcool ou droga. (2006b, 16 nov.). Folha de São Paulo, Folha On Line, Caderno Equilíbrio. Retirado em 31 jan. 2007, de http:/ /www1.folha.uol.com.br

Lloyd, G., \& Stead, J. (1998). From difference to deviance: The exclusion of gypsy-traveller children from school in Scotland. International Journal of Inclusive Education, 2(4), 359-369. Retirado em 22 fev. 2007, de http://www.scottishtravellered.net

Lloyd, G., \& Stead, J. (2001). The boys and girls not calling me names and the teachers to believe me: Name calling and the experiences of travelers in school. Children \& Society, 15(5), 361-374.

Lopes, A. A., Neto. (2005). Bullying: Comportamento agressivo entre estudantes. Jornal de Pediatria, 81(5), 164-172.

Maldade de menina. Comportamento. (2004, 22 set.). Istoé. Retirado em 31 jan. 2007, de http://www.terra.com.br/istoe

Marcuse, H. (2001). Comentários para uma redefinição da cultura. In H. Marcuse. Cultura e psicanálise. São Paulo, SP: Paz e Terra. (Original publicado em 1965)

Martins, M. J. D. (2005). O problema da violência escolar: Uma clarificação e diferenciação de vários conceitos relacionados. Revista Portuguesa de Educação, 18(1), 93-105.

Marx, K., \& Engels, F. (1998). A ideologia alemã. São Paulo, SP: Martins Fontes. (Original publicado em 1932)

Mercatelli, V. (2005). Bullying. Não tem a menor graça! Atrevida, 126. Retirado em 31 jan. 2007, de http://atrevida.uol.com.br

Ray, V., \& Gregory, R. (2001). School experiences of the children of lesbian and gay parents. Family matters - Australian Institute of Family Studies, 59, 28-34. Retirado em 22 jun. 2006, de http:/ /www.eric.ed.gov

Rede Globo Comunicação e Participações. (2005, 21 jun.). Mais Você [Programa de televisão]. Entenda do bullying. Retirado em 06 fev. 2007, de http://maisvoce.globo.com

Rede Globo Comunicação e Participações. (2006, 30 jan.). Mais Você [Programa de televisão]. O bullying pode causar sérios traumas. Retirado em 31 jan. 2007, de http://maisvoce.globo.com

Rigby, K. (2002). A meta-evaluation of methods and approaches to reducing bullying in pre-schools and early primary school in Australia. Canberra, Austrália: Attorney-General's Department. Retirado em 25 mar. 2006, de http:// www.crimeprevention.gov.au

Rouanet, S. P. (1998). Teoria, crítica e Psicanálise. Rio de Janeiro, RJ: Tempo Brasileiro.

Schäfer, M. (2005). Abaixo os valentões (S. Yumi, Trad.). Viver mente\&cérebro, 152. Retirado em 17 mar. 2006, de http:// www2.uol.com.br/vivermente

Sjöberg, R. L., Nilsson, K. W., \& Leppert, J. (2005). Obesity, shame and depression in school-aged children: A populationbased study. Pediatrics, 116(3), 389-392. Retirado em 22 jun. 2006, de http://www.pedistrics.org

Smith, P. K. (2002). Intimidação por colegas e maneiras de evitá-la. In E. Debarbieux \& C. Blaya (Eds.), Violência nas escolas e políticas públicas (pp. 187-205). Brasília, DF: Unesco.

Smith, P. K., Cowie, H., Olafsson, R. F., \& Liefooghe, A. P. D. (2002). Definitions of bullying: A comparison of terms used, and age and gender differences, in a fourteen-country international comparison. Child Development, 73(4), 1119-1133.

Sposito, M. P. (2001). Um breve balanço da pesquisa sobre violência escolar no Brasil. Educação e pesquisa, 27(1), 87-103.

Stein, M. T., Frasier, S. D., \& Stabler, B. (2004). Parent requests growth hormone for child with idiopathic short stature. Pediatrics, 114(5), Retirado em 22 jun. 2006, de http:// www.pedistrics.org

Veja como enfrentar o bullying entre estudantes. (2006, 16 nov.). Folha de São Paulo, Folha On Line, Caderno Equilíbrio. Retirado em 31 jan. 2007, de http://www1.folha.uol.com.br

Yoneyama, S., \& Naito, A. (2003). Problems with the paradigm: The school as a factor in understanding bullying (with special reference to Japan). British Journal of Sociology of Education, 24(3), 315-330.

Deborah Christina Antunes é mestre em Educação pela Universidade Federal de São Carlos e doutoranda em Filosofia pela mesma universidade. Endereço para correspondência: Universidade Federal de São Carlos, Centro de Educação e Ciências Humanas, Departamento de Educação, São Paulo, SP. deborahantunes@yahoo.com.br

Antônio Álvaro Soares Zuin possui graduação em Psicologia pela Universidade de São Paulo, mestrado em Educação pela Universidade Federal de São Carlos e doutorado em Educação pela Universidade Estadual de Campinas, com estágio doutoral em Filosofia da

Educação na Universidade Johann Wolfgang Goethe em Frankfurt am Main, Alemanha. Endereço para correspondência: Universidade Federal de São Carlos, Centro de Educação e Ciências Humanas, Departamento de Educação, Via Washington Luís, KM 235, São

Carlos, SP, 13 565-515. Caixa-Postal: 676. Tel.: (16) 3351 8365; Ramal: 8365; Fax: (16) 2608356. dazu@ufscar.br

\section{Do Bullying ao Preconceito: Os Desafios da Barbárie à Educação}

Deborah Christina Antunes e Antônio Álvaro Soares Zuin

Recebido: $12 / 04 / 2007$

$1^{a}$ revisão: 13/07/2007

Aceite final: 19/09/2007 